\title{
Qualimetric model for assessing the impact of the level of development of corporate information systems on the quality of aerospace instrumentation
}

\author{
Anatoliy Ovodenko ${ }^{1}$, Yan Ivakin $^{1,2,3}$, Elena Frolova $^{1, *}$, and Maria Smirnova ${ }^{1}$ \\ ${ }^{1}$ Saint-Petersburg State University of Aerospace Instrumentation, 190000, 67, Bolshaya Morskayastr, Saint-Petersburg, Russia \\ ${ }^{2}$ «Concern “Oceanpribor”»JSC, 1197376, 46, Chkalovsky prospect, Saint Petersburg, Russia \\ ${ }^{3}$ Saint-Petersburg Institute for Informatics and Automation of the Russian Academy of Sciences, 199178, 39, 14 line, Saint Petersburg, \\ Saint Petersburg, Russia
}

\begin{abstract}
In the context of the digital transformation of the economy, the effective development of corporate information systems of research and production holdings of aerospace instrumentation is becoming one of the decisive factors in ensuring the high quality of domestic avionics. This article is devoted to the analysis of the influence factor of digitalization and informatization processes in scienceintensive industries of modern aerospace instrumentation, as well as the definition of a qualimetric model for assessing its impact on the quality of domestic avionics products in the current economic and technological conditions. The influence of the level of development of corporate information systems of aerospace instrumentation enterprises on the quality of domestic avionics products is assessed in the article on the basis of the corresponding hierarchy of quality indicators. The proposed model of the influence of the level of development of corporate information systems on the quality of aerospace instrumentation products assumes the choice of the form of the integral criterion depending on the external requirements for the efficiency of the assessment, the sensitivity of the system of quality indicators.
\end{abstract}

\section{Introduction}

The economic and technological course towards the digital transformation of the country's industrial sphere has found its direct expression, first of all, in the development of various industrial information systems and automation complexes. This is primarily manifested in:

- rejection of the "blind" copying of ready-made organizational and technical patterns for the creation (deployment) of systems for informatization of enterprise management bodies, offered by Western developers;

- orientation of basic software solutions for informatization of enterprises, automation of technological processes to the Russian system of standards for organizing production, taking into account the specifics of domestic industrial relations;

- ensuring technological independence, the possibility of development and information security of domestic developments of software and technical solutions, which in practice is expressed in the possession of all the components of the required software technologies: from the initial logical and algorithmic models to the compiled code of software components.

In modern works on informatization (digitalization) of production, automation of technological processes, such as $[1,2,3]$, the term "corporate information system" (CIS) is used to denote the integral essence of a computer system for processing and storing information, which to the greatest extent covers various aspects of the life of enterprises.

Today, the effectiveness of the functioning of the CIS is increasingly affecting the provision of the required quality level of aerospace instrumentation products. The methods of modern qualimetry make it possible to quantitatively describe and evaluate the constructive effect of the development of the CIS of aerospace instrumentation enterprises, which is brought into the quality of domestic avionics products.

\section{Principles of formation and development of corporate information systems}

The main principles of the modern approach to the formation and development of the CIS of instrumentmaking enterprises include:

1. Activity. This principle is expressed in the constant consideration of the fact that the CIS and its constituent subsystems are in continuous development. Today, the functionality of instrument-making enterprises subject to automation is constantly expanding; ideas about the

*Corresponding author: frolovaelena@mail.ru 
possibilities of information technology are changing in almost all areas of human activity, etc.;

2. Specificity. In the presence of basic software and organizational and technical solutions for automating business processes of an enterprise, the proposed approach prioritizes taking into account the narrow specifics of management organization at each specific enterprise. In fact, this principle denotes the research nature of the final, concretized development of applied functionality for the CIS of a separate instrumentmaking enterprise;

3. Prototyping. Feasibility on a competitive basis. ideal organizational and organizational-technical patterns, abstractly described by developers of software solutions, in the form of prototypes of applied functional adapted to the conditions of a particular enterprise;

4. Pragmatism. Focus on the targeted efficiency of the processes of formation and development of corporate information systems, i.e. focus on gaining an increase in the target activity of the instrument-making enterprise. This principle, in a sense, is the opposite in meaning to the term "academic".

5. Progressiveness. Postulating as a natural fact of the impossibility of achieving the goals of automation at a time, denying the one-act nature of the implementation of ideal digitalization models in enterprises that have developed in the pre-digital era. The formation and development of CIS, with the current level of coverage of the functionality of instrument-making enterprises, is a multi-stage process that affects not only the technical and organizational aspects of the life of enterprises, but also the psychology of each of their employees.

The basic concept in the formation and development of corporate information systems for an aerospace instrumentation enterprise within the framework of the proposed approach is an adequate modeling of the entire set of enterprise business processes, detailed and taking into account the specifics of their implementation in each specific case. Unlike other known approaches, the proposed approach does not use the current, artificially postulated organizational formalisms as a basic conceptual model. As practice shows, these formalisms are rather unstable grounds for the design and creation of CIS of high-tech instrument making enterprises [4, 5].

The methods of modern qualimetry make it possible to quantitatively describe and evaluate the constructive effect of the development of the CIS of aerospace instrumentation enterprises, which is brought into the quality of domestic avionics products. In their thematic totality, the components of such methods are considered within the framework of this article as an appropriate qualimetric model.

The influence of the level of development of the CIS of aerospace instrumentation enterprises on the quality of domestic avionics products is assessed on the basis of the corresponding hierarchy of quality indicators [6]. The estimates of each simplest indicator are further collapsed into estimates of the summary and integral quality indicators of aerospace instrumentation products using appropriate weighting factors reflecting the importance of each simpler indicator in the convolution of a more complex summary quality indicator.

\section{Mathematical model of the influence of the level of development of the corporate information systems on the quality of aerospace instrumentation products}

The mathematical essence of this convolution consists in the sequence of aggregation of the simplest (directly assessed or measured) quality indicators $\left\{q_{i}\right\}$, through the summary indicators $\left\{\bar{q}_{i j}\right\}$, into the most complex integral indicator: $Q_{0}=$ "quality of aerospace instrumentation product". Accordingly, the essence of the quality assessment process according to the described system of indicators consists in sequential: direct assessment by experts (s) of the simplest quality indicators $\left\{q_{i}\right\}$ and multi-stage convolution of the values of the simplest indicators into consolidated $\left\{\bar{q}_{i j}\right\}$ and integral $Q_{0}$. In turn, a direct assessment of the values of the simplest indicators $\left\{c\left(q_{i}\right)\right\}$ proceeds from the fact that:

Equations should be centred and should be numbered with the number on the right-hand side.

$$
c\left(q_{i}\right)=\xi,-\xi
$$

where $\xi^{\prime}$ - some value of the quality indicator $\mathrm{q}_{\mathrm{i}}$ in the ideal model for the implementation of an aerospace instrument-making product, reproduced in the mind of an expert during an assessment (an act of noninstrumental measurement);

$\xi$ - the current observed (registered) state of the quality indicator $\mathrm{q}_{\mathrm{i}}$ for the version of the implementation of the aerospace instrument-making product observed by the expert.

Immediate values $\left\{c\left(q_{i}\right)\right\}$ relate directly to the ordinal scale [0:10], which is described in detail and substantiated in [Ошибка! Источник ссылки

не найден.]. All values of the assessment of the summary $\left\{\bar{q}_{i j}\right\}$ and the integral quality indicator $Q_{0}$ are related to the scale [0:10], which ensures the unity of such a "non-instrumental", in the terminology of works $[7,8]$ "soft" measurement in the system of product quality indicators aerospace instrumentation. Within the framework of the qualimetric model of the influence of the level of development of the CIS on the quality of aerospace instrumentation products, it is the subjectively-fast nature of the soft evaluation of the simplest indicators $\left\{q_{i}\right\}$ that ensures the ease and efficiency of the entire procedure of qualimetric analysis of the quality of the specified products. Obvious disadvantages, namely, the subjectivity of the assessment, is compensated by the repetitiveness and repeatability of the assessment procedures as the quality of these products improves.

It is the above approach to assessing the simplest indicators that provides avoiding the methodological "heavyness" of traditional methods for assessing the 
quality of aerospace instrumentation products. Obviously, the summary indicators $\left\{\bar{q}_{i j}\right\}$ are calculated according to the values of the simplest indicators $\left\{q_{i}\right\}$ of the quality of aerospace instrumentation products, taking into account the index of compositional importance $\left\{w_{i}\right\}$. The index of compositional importance $w_{i}$ is a complex indicator, the value of which shows the importance, weight, significance, etc. of this i-th indicator $q_{i}$ in aggregated (convolutional) combination with other indicators as part of a more complex summary indicator. Local indices of compositional importance $\left\{w_{i}\right\}$ are allocated - i.e. indices fixing the importance in the composition of the closest aggregate indicator $\bar{q}_{i}$, and generalized indices of compositional importance $\left\{u_{i}\right\}$ - i.e. indices fixing the importance in the composition of the integral quality index of an aerospace instrument-making product - $Q_{0}$. At the same time, the indicated types of compositional importance indices are related by the following mathematical relationship:

$$
U_{p}=\prod_{i=1}^{p} w_{i}
$$

where $p$ - the number of levels of aggregation of the simplest indicators qi when folding into a consolidated (integral) quality indicator of an aerospace instrumentmaking product - $Q_{0}$.

The following mathematical properties of the indices of compositional importance $\left\{w_{i}\right\}$ of indicators $\left\{q_{i}\right\}$ of the quality of aerospace instrumentation products have been determined:

- are defined on the unit interval of real numbers:

$$
\begin{gathered}
w_{i} \in(0 ; 1), \\
w_{i} \in R,
\end{gathered}
$$

- normalized within one composition into a summary indicator:

$$
\sum_{i=1}^{z} w_{i}=1
$$

where $z$ - the number of simpler indicators $\left\{\bar{q}_{i j}\right\}$ in the convolution into a more complex composite indicator $q_{i}$ of the quality of an aerospace instrumentation product. The mathematical and logical submodel for establishing and calculating the indices of the compositional significance of the indicators $\left\{q_{i}\right\}$ in the consolidated and integral quality indicators $Q_{0}$ is given in [Ошибка! Источник ссылки не найден.].

The presence of the estimates of the simplest quality indicators $\left\{c\left(q_{i}\right)\right\}$, obtained from experts, and their indices of compositional importance $\left\{w_{i}\right\}$ makes it possible to link mathematically the indicated values of the estimates with the values of the summary $\left\{\bar{q}_{i j}\right\}$ and integral estimates $Q_{0}$ of the quality of an aerospace instrument-making product through the forms of the integral quality criterion.

\section{Integral criterion for assessing the impact of the level of development of corporate information systems on the quality of aerospace instrumentation products}

Assessment of the quality of aerospace instrumentation products does not imply the use of a single, standardized form of integral quality criterion. In the basic version, it is supposed to use the integral form based on the additive convolution:

$$
Q_{0}=\sum_{i=1}^{m} w_{i} \cdot c\left(q_{i}\right)
$$

wherem' - the number of simpler indicators as part of their aggregated convolution into a more complex indicator.

The disadvantage of the mathematical form (6) is obvious: it allows the so-called "natural" compensation for low values for some quality indicators $\left\{q_{i}\right\}$ due to high values for other indicators in the composition. If this drawback is significant within the framework of the quality system of the technology for the development of this or that product of aerospace instrumentation, then the mathematical form of the integralcriterion thatimplements the multiplicative convolution is used:

$$
Q_{0}=\prod_{i=1}^{m^{\prime}} w_{i} \cdot c\left(q_{i}\right)
$$

Obviously, with this form of mathematical linking of the simplest indicators $\left\{q_{i}\right\}$ with the summary $\left\{\bar{q}_{i j}\right\}$ and integral $Q_{0}$ indicators of the quality of aerospace instrumentation products, the system of these indicators will be very "sensitive", i.e. zeroing at least one elementary quality indicator will lead to zeroing and the integral quality indicator. The combined forms of the integral quality criterion for aerospace instrumentation products will have intermediate mathematical properties:

1) additive-multiplicative:

$$
Q_{0}=\sum_{j=1}^{n^{\prime}}\left(\prod_{i=1}^{m^{\prime}} w_{i} \cdot c\left(q_{i}\right)\right)_{j}
$$

i.e. assuming a multiplicative convolution in a number of compositions of summary indicators from the simplest indicators (level 1) to a certain level $m$ ' with their further additive convolution into an integral indicator $Q_{0}$ of the quality of aerospace instrumentation products;

2) multiplicative-additive:

$$
Q_{0}=\prod_{j=1}^{n^{\prime}}\left(\sum_{i=1}^{m^{\prime}} w_{i} \cdot c\left(q_{i}\right)\right)_{j}
$$

i.e. alternatively to option 1), which assumes additive convolution in the compositions of summary indicators 
from the simplest to a certain level m' with their further multiplicative convolution into an integral quality indicator.

The proposed model of the influence of the level of development of the CIS on the quality of aerospace instrumentation products assumes an independent and justified choice of any form of integral criterion from (6) - (9), depending on external requirements for the efficiency of the assessment, the sensitivity of the system of quality indicators, etc.

In the traditional practice of quality services, for simplicity of mathematical descriptions, it is rational to use a particular version of the additive form of the integral quality criterion for aerospace instrumentation products - the form of linear convolution:

$$
Q_{0}=\sum_{i=1}^{n^{\prime}} w_{i} q_{i}
$$

As mentioned earlier, the values of the estimates c(qi) are the result of the examination according to the scale shown in [8], and the values of the compositional importance indices, as normalized values, are determined within the framework of the corresponding preparatory procedures.

\section{Conclusion}

The need to develop a theoretically harmonious set of principles and methods for creating an integrated information system for aerospace instrumentation enterprises, to ensure the improvement of the quality of domestic avionics products is a current urgent task [911]. A proactive approach to the creation of the specified CIS is a fairly well-grounded scientifically and practically tested coherent concept of building the desired system. The construct of this approach is to recognize the domination of the internal needs of the design and production organization in automation and digitalization of its management over the external causes of initiation. [13-16]

Further directions for the development and improvement of a proactive approach to the development and creation of CIS of aerospace instrumentation enterprises in order to improve the quality of avionics products are: detailing the specific methodological apparatus for designing specific software and hardware solutions, developing narrowly focused methods for automating technological processes in aerospace instrumentation, creating standard software and information solutions. This will open up broad prospects for the implementation of the proposed approach in the process of forming the CIS of various aerospace instrument-making enterprises, the practice of the corresponding instrument-making concerns, as well as in the methodological apparatus of practical measures for digital transformation of high-tech instrument-making enterprises in the Russian Federation.

\section{References}

[1] Ya. Sovietov, S.A. Yakovlev, System modeling (Moscow, Yurayt Publishing House, 2019)

[2] R.M. Yusupov, V.P. Zabolotsky, Conceptual and scientific and methodological foundations of informatization (Saint Petersburg, Nauka, 2009)

[3] B.Ya. Sovietov, V.V. Tsekhanovsky, Information technologies (Moscow, Yurayt Publishing House, 2016)

[4] A.V. Shatokhin, Ya.A. Ivakin, Information infrastructure to support the operation of hydroacoustic weapons of the Navy by the enterprises of marine instrument making, Hydroacoustics 42, 2 (2020)

[5] V.I. Vorotnikov, A.V. Vohmyanina, The method of linearizing feedback in the control problem with respect to part of the variables under uncontrolled interference, Proceedings of SPIIRAS 6, 61 (2018)

[6] E. Gorbashko, A. Frolkov, Assessment of the quality of interaction in the digital economy, Standards and Quality 2 (2020)

[7] F. Wasserman, Neurocomputer technology: Theory and practice (Moscow, Mir, 1992)

[8] T. Saati, K. Kearns, Analytical planning, Organization of systems (Moscow, Radio and communication, 1991)

[9] P. Tiwari, J.K. Sadeghi, C. Eseonu, A sustainable lean production framework with a case implementation: Practice-based view theory, Journal of Cleaner Production 277, 123078 (2020)

[10] A. Amrani, Y. Ducq, Lean practices implementation in aerospace based on sector characteristics: methodology and case study, Production Planning and Control 31, 16, 1313-1335 (2020)

[11] J. Yang, X. Li, S. Huang, Impacts on environmental quality and required environmental regulation adjustments: A perspective of directed technical change driven by big data, Journal of Cleaner Production 275, 124126 (2020)

[12] V. Scuotto, A. Garcia-Perez, C. Nespoli, A. MesseniPetruzzelli, A repositioning organizational knowledge dynamics by functional upgrading and downgrading strategy in global value chain, Journal of International Management 26, 4, 100795 (2020)

[13] X. Guo, B. Reithel, Information-Processing Support Index: A New Perspective on IT Usage, Journal of Computer Information Systems 60, 6, 541-554 (2020)

[14]L. Xu, X. Peng, R. Pavur, V. Prybutok, Quality management theory development via meta-analysis, International Journal of Production Economics 229, 107759 (2020)

[15] J.L. García-Alcaraz, F.J.F. Montalvo, L. AvelarSosa, M.M. Pérez de la Parte, J. Blanco-Fernández, E. Jiménez-Macías, The importance of access to information and knowledge coordination on quality 
and economic benefits obtained from Six Sigma Wireless Networks 26, 8, 5713-5726 (2020)

[16]E. Raguseo, C. Vitari, F. Pigni, Profiting from big data analytics: The moderating roles of industry concentration and firm size, International Journal of Production Economics 229, 107758 (2020) 